\title{
Phase Evolution During One-pot Synthesis of Amine Modified Mesoporous Silica Materials: Preparation, Properties, Carbon Dioxide Adsorption
}

Dol:

10.1016/j.apsusc.2019.01.146

\section{Document Version}

Accepted author manuscript

Link to publication record in Manchester Research Explorer

Citation for published version (APA):

Zelenak, V., Skínska, M., Siperstein, F., \& Patti, A. (2019). Phase Evolution During One-pot Synthesis of Amine Modified Mesoporous Silica Materials: Preparation, Properties, Carbon Dioxide Adsorption. Applied Surface Science. https://doi.org/10.1016/j.apsusc.2019.01.146

Published in:

Applied Surface Science

\section{Citing this paper}

Please note that where the full-text provided on Manchester Research Explorer is the Author Accepted Manuscript or Proof version this may differ from the final Published version. If citing, it is advised that you check and use the publisher's definitive version.

\section{General rights}

Copyright and moral rights for the publications made accessible in the Research Explorer are retained by the authors and/or other copyright owners and it is a condition of accessing publications that users recognise and abide by the legal requirements associated with these rights.

\section{Takedown policy}

If you believe that this document breaches copyright please refer to the University of Manchester's Takedown Procedures [http://man.ac.uk/04Y6Bo] or contact uml.scholarlycommunications@manchester.ac.uk providing relevant details, so we can investigate your claim.

\section{OPEN ACCESS}




\title{
Phase Evolution During One-pot Synthesis of Amine Modified Mesoporous Silica Materials: Preparation, Properties, Carbon Dioxide Adsorption
}

Vladimír Zeleň́k $^{1 *}$, Mária Skř́nskka ${ }^{1}$, Flor R. Siperstein ${ }^{2}$, Alessandro Patti ${ }^{2}$

${ }^{1}$ Department of Inorganic Chemistry, Faculty of Science, P. J. Šafárik University, Moyzesova 11, SK-041 54 Košice, Slovak Republic

${ }^{2}$ School of Chemical Engineering and Analytical Science, The University of Manchester, Sackville Street, Manchester M13 9PL, United Kingdom

*Corresponding author: e-mail: vladimir.zelenak@upjs.sk

\begin{abstract}
Amino-functionalized mesoporous MCM-41 materials were synthesized by co-condensation of amino-organosiloxane precursors, namely 3-aminopropyltrimethoxysiloxane (APS), 3(methylamino)propyltrimethoxysiloxane (MAPS) and 3-(phenylamino)propyltrimethoxysiloxane (PAPS) with tetraethyl orthosilicate (TEOS) in water solution containing ammonia and in the presence of surfactant as templating agent. The ratio of amino-organosiloxanes to TEOS in the synthesis mixture was 3, 5, 10, 20 and $30 \mathrm{wt} \%$. The prepared samples were characterized by Small Angle X-ray Scattering (SAXS), High-Resolution Transmission Electron Microscopy (HRTEM), Thermogravimetric Analysis (TGA) and $\mathrm{N}_{2}$ adsorption/desorption. It followed from the measurements that the ordered porous materials of hexagonal symmetry were obtained at small ratios of APS and MAPS to TEOS (3, 5, $10 \mathrm{wt} \%$ ). At larger ratios (20 and $30 \mathrm{wt} \%$ ), disordered or non-porous amorphous amino-functionalized silica particles were obtained. For the PAPS precursor, hexagonally-packed structures were observed up to a PAPS to TEOS ratio of $30 \mathrm{wt} \%$, when a transition to a lamellar phase occurs. The reasons of the structural changes are discussed in terms of modifications in the effective shapes of the cylindrical micelle aggregates, caused by different hydrophilicity/hydrophobicity of the used amine precursors and their interactions with surfactant micelles. To better understand the origin of this behavior, lattice Monte Carlo simulations of simple coarse-grained surfactant solutions were performed. All prepared samples were used to study $\mathrm{CO}_{2}$ adsorption. It was found that $\mathrm{CO}_{2}$ adsorption capacity in the samples increased with the increasing concentration of amino-organosiloxane precursor, independently of
\end{abstract}


the surface area. These results imply that $\mathrm{CO}_{2}$ adsorption primarily takes place on amine active centers and physical adsorption, which is dependent on the high surface area, plays a less important role in $\mathrm{CO}_{2}$ adsorption on these materials.

Keywords: mesoporous silica; self-assembly; co-condensation; amino-organosiloxanes; carbon dioxide adsorption 


\section{Introduction}

Self-organized aggregates of surfactants and block copolymers are widely used in chemistry as structure directing media in the synthesis of a variety of nanostructured materials [1]. These aggregates of surfactants are used as templates, whose size and structure determine the properties of the newly-formed material. In the last two decades, a great deal of scientific attention was paid to the synthesis of systems containing mixed inorganic and organic components, in which organic structure-directing agents interact with the inorganic component across a hydrophobichydrophilic interface to achieve desirable macroscopic properties in the final product material [2].

Soon after the first synthesis of the mesoporous silica MCM-41 by Beck, Kresge, and coworkers in $1992[3,4]$, this approach led to a series of discoveries in materials chemistry. By adjustment of the synthesis conditions, ordered mesoporous materials with various hexagonal (MCM-41), cubic (MCM-48) and lamellar (MCM-50) structures were prepared. All three phases in the M41S family can be synthesized by slightly varying the reaction conditions, but the stability decreases in the order: lamellar phase, hexagonal MCM-41, cubic MCM-48 [5].

With the goal of extending the range of properties of self-assembled nanoporous materials, further scientific attention focused on producing hybrid inorganic-organic solids in which an organic moiety (e.g. amine ligand) is covalently linked to the silica backbone. The incorporation of the organic ligands is usually carried out in two ways: a.) by covalent binding of the ligands on the inorganic walls of the material by treatment of the calcined porous materials with organosiloxanes (i.e. post-synthesis treatment, called grafting) [6]; b.) by direct incorporation of the organic functions during the synthesis process, involving co-condensation of tetraalkoxysiloxanes, such as tetraethyl orthosilicate (TEOS), with organosiloxanes, such as 3aminopropyltriethoxysilane (i.e. one-pot synthesis) [7]. The former synthesis pathway has several shortcomings. First, the attachment of a layer of functional groups on the pore surface results in a reduced pore size and pore volume, being often undesired as it can lead to pore blockage. Secondly, the loading level of the functional groups, which can be grafted on the surface, is limited because of the limited density of the reactive surface silanols [8]. Moreover, grafting is significantly hindered because of the restricted access to most of the surface active groups located in the microporous domains of the material $[7,8]$.

Compared with the post-synthesis grafting, the co-condensation method presents several advantages, such as homogeneous distribution of the amine groups, controllable incorporation 
amount and avoidable pore blockage [9-12]. Co-condensation offers a higher and more uniform surface coverage of functional groups and a better control over the surface properties of the resultant materials [9-12]. This method has been widely employed to functionalize the mesoporous materials by various functional groups, such as aliphatic hydrocarbon, phenyl, thiol, amine, sulfonic groups, etc. [10, 13-17]. However, sometimes, especially at higher concentrations of organosiloxanes, the co-condensation may lead to nonporous or microporous solids [7, 18].

Our interest focuses on the use of ordered nanoporous silica materials for carbon dioxide adsorption. It is well documented that functionalization of porous silica with amine ligands leads to the formation of solid porous materials with high affinity to carbon dioxide. Different types of amines (mono-, di-, tri-, polyamines) were used for the silica functionalization [19-24]. In such materials, the adsorption of carbon dioxide is related to amount of the surface amine centers, amine surface density [25-31], but the adsorption of carbon dioxide is influenced also by the basicity of amine ligands [32], the dimensionality of the silica matrix [33] as well as by entropy-driven effects [34].

In our previous work, dealing with the influence of amine basicity on carbon dioxide adsorption [32], we found that the carbon dioxide sorption capacities ranged between $0.68 \mathrm{mmol} / \mathrm{g}$ and $1.04 \mathrm{mmol} / \mathrm{g}$, depending on the type of amine. In the light of these results, our interest turned to the effect of incorporating a larger amount of functional groups into the mesoporous silica materials, while using the same amine ligands. Since the co-condensation offers the possibility of homogeneous distribution of the amine groups and their controllable incorporation, in the present work we have focused on the one-pot synthesis of MCM-41-like materials modified with different amines. For the co-condensation with TEOS, we have used the three amino-organosiloxanes reported in Scheme I, namely 3-aminopropyltrimethoxysiloxane (APS), 3(methylamino)propyltrimethoxysiloxane (MAPS) and 3-(phenylamino)propyltrimethoxysiloxane (PAPS), with the aim of producing materials with hexagonal symmetry and high amine loading. We have observed that the ordered porous structures were obtained only at small ratios of aminoorganosiloxane precursors to TEOS and, in some cases, a phase change from the hexagonal to lamellar structure was observed. Even though the synthesis of amine modified silica materials prepared by co-condensation method has been described in the literature, to the best of our knowledge, a comparative study of the influence of concentration of three different amines (APS, MAPS, PAPS) on the phase evolution of the resulting material is missing. Not only does our work 
report on the synthesis and structural properties of MCM-41-like porous materials, but it also provides an additional insight from molecular simulation, which is key to understand some details that are not easily accessible by experiments. Moreover, to test the performance of our materials, we also analyse their ability of adsorbing carbon dioxide under a spectrum of conditions.

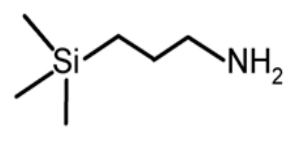

APS

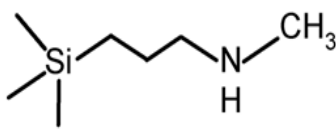

MAPS

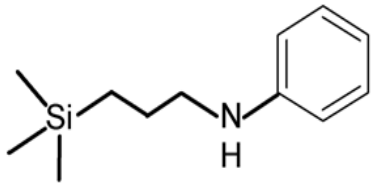

PAPS

Scheme 1. Amine precursors used in the study.

\section{Experimental}

All chemicals were purchased from Sigma-Aldrich ${ }^{\circledR}$ and used as received without further purification. TEOS (97\%) was used as silica source and cetyltrimethylammonium bromide (CTAB) was used as the structure directing agent. APS, MAPS, PAPS were used as a sources of amines (see Scheme 1). These amino-organosiloxanes were mixed with TEOS in different wt $\%$ ratios during the synthesis.

\subsection{Synthesis}

Amine modified mesoporous silica materials with different content of amines were prepared by a room-temperature one-pot synthesis by adjusting the ratio of TEOS and Xtrimethoxysiloxane in the synthesis gel, where $X=3$-aminopropyl (AP), 3-(methylamino)propyl (MAP), or 3-(phenylamino)propyl (PAP). In a typical synthesis, $0.0132 \mathrm{~mol}$ of CTAB was dissolved in a mixture of $13.76 \mathrm{~mol}$ of water and $0.41 \mathrm{~mol}$ of aqueous ammonia (26\%). The solution was stirred at $400 \mathrm{rpm}$ for $30 \mathrm{~min}$. Then, $0.033 \mathrm{~mol}$ of mixture of TEOS with respective X-trimethoxysiloxane was added. The X-trimethoxysiloxane / TEOS ratio in the mixture was 3, 5, 10,20 or $30 \mathrm{wt} \%$. The mixture was stirred for $10 \mathrm{~h}$. Then, the resulted solid was recovered by filtration, repeatedly washed with distilled water and dried at room temperature. The obtained samples were denoted as MCM41-nX, where $\mathrm{n}=0,3,5,10,20,30$, according to the wt $\%$ ratio of APS, MAPS, PAPS to TEOS in the synthesis gel. The final materials were prepared by extraction of the samples in absolute ethanol, three times for $24 \mathrm{~h}$. It was observed that during the extraction the sample MCM41-30PAP dissolved and only non-porous amorphous silica was recovered after 
total solvent evaporation. As it was shown by further studies (see below), this was due to the lamellar character of the as-synthesised sample.

\subsection{Methods of characterization}

SAXS experiments were carried out at B1 Hasylab beam line (DESY Hamburg) with the beam energy $12 \mathrm{keV}(\lambda=1.03 \AA)$ using PILATUS detector.

HRTEM micrographs were taken with a JEOL JEM 3010 (LaB 6 cathode) microscope operated at $300 \mathrm{kV}$. Carbon coated copper grid was used to prepare samples for the TEM observation. A powdered sample was dispersed in ethanol and the suspension was treated in an ultrasonic bath for $10 \mathrm{~min}$.

Thermal characterization was carried out using STA Netzch 409PC apparatus under dynamic conditions with heating rate $9^{\circ} \mathrm{C} / \mathrm{min}$ in atmosphere of air $\left(20 \mathrm{~cm}^{3} / \mathrm{min}\right)$ using simultaneous thermal analysis (STA) with TGA / differential thermal analysis (DTA) sample holder.

Nitrogen adsorption/desorption experiments were measured with a Quantachrome Nova Automated Gas Sorption System at $77 \mathrm{~K}$. Prior to adsorption, samples were outgassed under vacuum for $24 \mathrm{~h}$ at $110^{\circ} \mathrm{C}$.

The $\mathrm{CO}_{2}$ sorption capacities were determined by a thermogravimetric balance Netzsch 409PC by STA using TGA / differential scanning calorimetry (DSC) sample holder, allowing TGA/DSC to be applied simultaneously to the same sample. The sample size of $20 \mathrm{mg}$ was used. The $\mathrm{CO}_{2} / \mathrm{N}_{2}$ certified gas mixture containing $10 \%$ of carbon dioxide, purchased from Linde gas, was used for the sorption study. The composition of the mixture resembled the concentration of $\mathrm{CO}_{2}$ in the flue gas, where concentration is ranging from $10 \%$ to $15 \%$ [35]. The flow rate of $\mathrm{CO}_{2} / \mathrm{N}_{2}$ mixture was $20 \mathrm{~cm}^{3} / \mathrm{min}$. Initial activation of the amine modified samples was performed by their heating at $110^{\circ} \mathrm{C}$ for $3 \mathrm{~h}$ in inert gas $\left(\mathrm{N}_{2}\right)$.

\section{Results and discussion}

As mentioned above, there are two main methods to modify periodic nanoporous silica (PNS) by amine functionalities: grafting and one-pot synthesis. The method of grafting is based on the reaction of surface hydroxyls of PNS with alkoxysiloxanes bearing organic functional group 
(e.g. amine). Therefore, the amount of grafted ligands (amines), as active sites for carbon dioxide capture, strongly depends on the amount of the surface hydroxyls.

Another approach to load various amounts of amines on the silica surface, independently on the surface hydroxyls, is based on the one-pot synthesis pathway, where the amine functionality is added directly to the synthesis gel. In this work, we have used the one-pot synthesis approach to obtain MCM-41 silicas modified by AP, MAP and PAP. The X-trimethoxysiloxane/TEOS ratio in the mixture was 3, 5, 10, 20 and $30 \mathrm{wt} \%$. It was observed that the amine concentration and the amine type influenced the porosity and long-range order of the prepared materials. Ordered materials were obtained only in small ratios of amino-organosiloxanes to TEOS in the case of APS and MAPS precursors. In PAPS modified material, the ordered structure was observed at all the ratios investigated, but a phase transition from the hexagonal to lamellar phases was observed for the sample containing $30 \mathrm{wt} \%$ of PAPS. Due to its lamellar arrangement, this sample was found to be especially unstable after template extraction, resulting into the collapse of the organicinorganic phase and lack of a suitable porous network.

\subsection{SAXS analysis}

The long-range order of prepared mesoporous silica materials was studied by SAXS, whose patterns are reported in Fig. 1. In particular, Figs. 1a-c show normalized SAXS patterns of parent material MCM-41 as well as the samples modified with APS, MAPS and PAPS. The SAXS pattern of unmodified MCM-41 silica exhibits a strong peak at $q=0.181 \AA^{-1}$ and weak peaks at $q=0.322$, 0.372 and $0.482 \AA^{-1}$ (Fig. 1). These four peaks can be indexed as (10), (11), (20) and (21) in a hexagonal unit cell with point group $\mathrm{p} 6 \mathrm{~mm}$.

After the addition of 3 and $5 \mathrm{wt} \%$ of the amino-organosiloxane precursors (APS, MAPS or PAPS) into a synthesis gel, a well ordered mesoporous MCM-41-like structure was preserved (see SAXS patterns of the samples MCM41-3AP, MCM41-5AP in Fig. 1a, MCM41-3MAP, MCM415MAP in Fig. 1b and MCM41-3PAP, MCM41-5PAP in Fig. 1c). Diffraction peaks originating in hexagonal symmetry could be easily distinguished in the SAXS patterns of respective materials (Figs. 1a-c). 


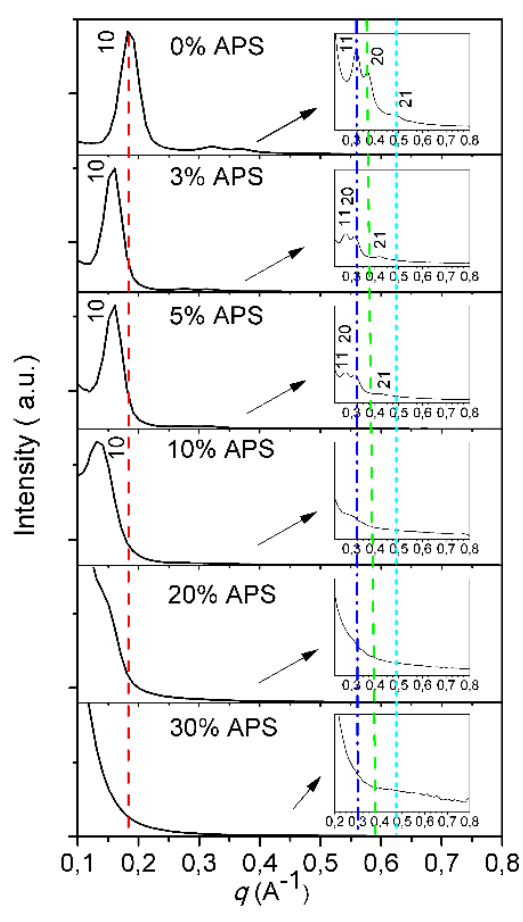

a

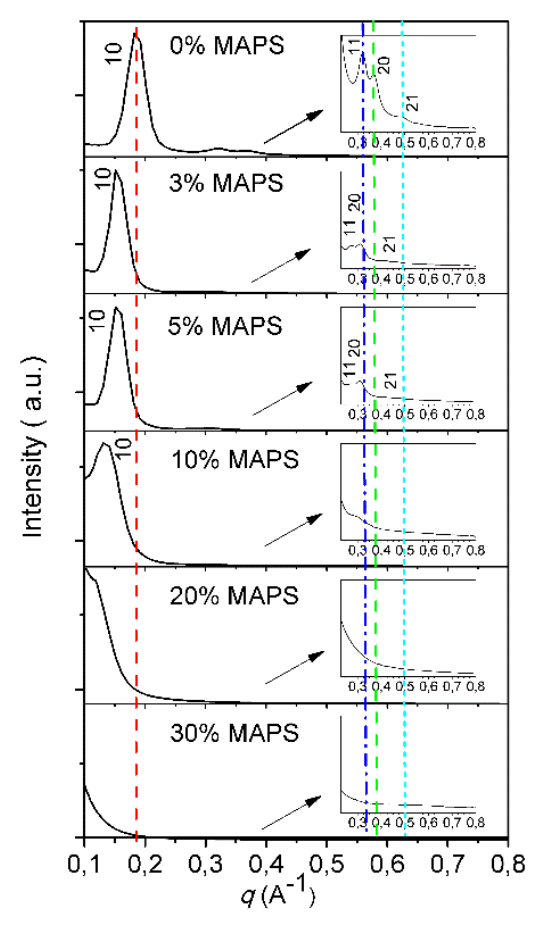

b

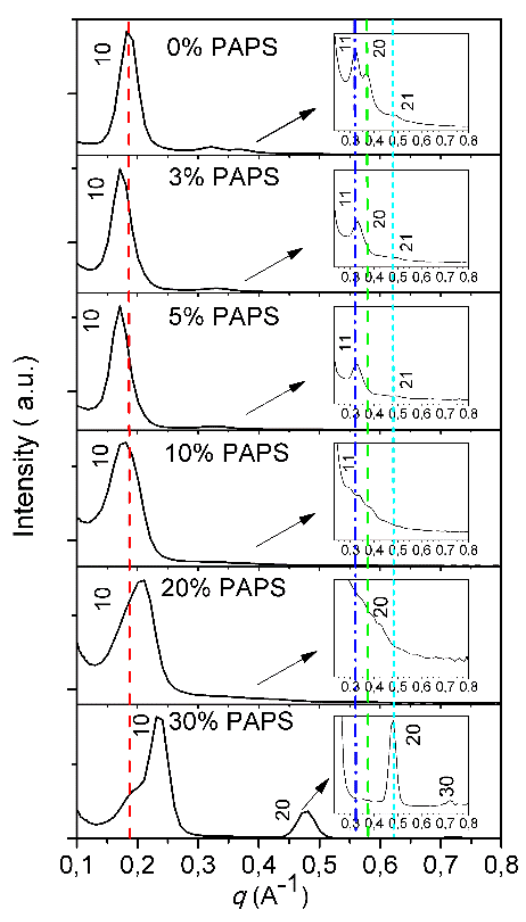

C

Figure 1. SAXS patterns of MCM-41 silicas modified with a) APS; b) MAPS; c) PAPS. The vertical colour lines are displayed for eye guidance only.

A larger amine concentration (10 wt $\%$ ) caused the decrease of the structural order, which was reflected by the broadening of the (10) diffraction peak in the samples MCM41-10AP, MCM41-10MAP and MCM41-10PAP. At higher concentration of APS and MAPS precursors (20 and $30 \mathrm{wt} \%$ ), the SAXS patterns indicated that structures showed no long-range structural order. For the PAP modified sample, the trend was similar to AP and MAP modified samples at lower concentrations of amine precursor $(3,5,10 \mathrm{wt} \%)$. However, at the PAPS concentration of $20 \%$, the peak (10) was still present (in contrast to AP and MAP modified materials), but it was shifted to higher $q$ values in comparison with pure MCM41 (see Fig. 1c). At the PAPS concentration of $30 \mathrm{wt} \%$, the phase transformation from the hexagonal to lamellar $\mathrm{L}_{\alpha}$ phase was observed. These results are also supported by HRTEM micrographs (Fig. 4) and Nitrogen adsorption/desorption experiments (see sections 3.2 and 3.3). Moreover, it was observed that during the template removal and the extraction in ethanol, the sample MCM41-30PAP was dissolved and only non-porous silica was recovered after solvent evaporation. This behaviour confirms the suggested lamellar phase of the as-synthesised sample MCM41-30PAP. 
The addition of amines into to the synthesis gel increased the unit cell parameter in the AP and MAP modified samples, indicated by the shift of the peaks in SAXS patterns to lower $q$ values in comparison with unmodified MCM41 (see Fig. 1 a.b, the concentrations of amines 3, 5, 10 $w t \%)$. At higher amines concentration, no diffraction peaks were observed (although at the concentrations of APS and MAPS of $20 \mathrm{wt} \%$ small shoulder still remained), suggesting that these samples do not show a regular long-range ordered porous structure. The change of unit cell parameter, calculated for the respective samples from the (10) peak in the SAXS patterns and according to the equation: $a=2 * d_{100} / \sqrt{3}$, is depicted in Fig. 2 .

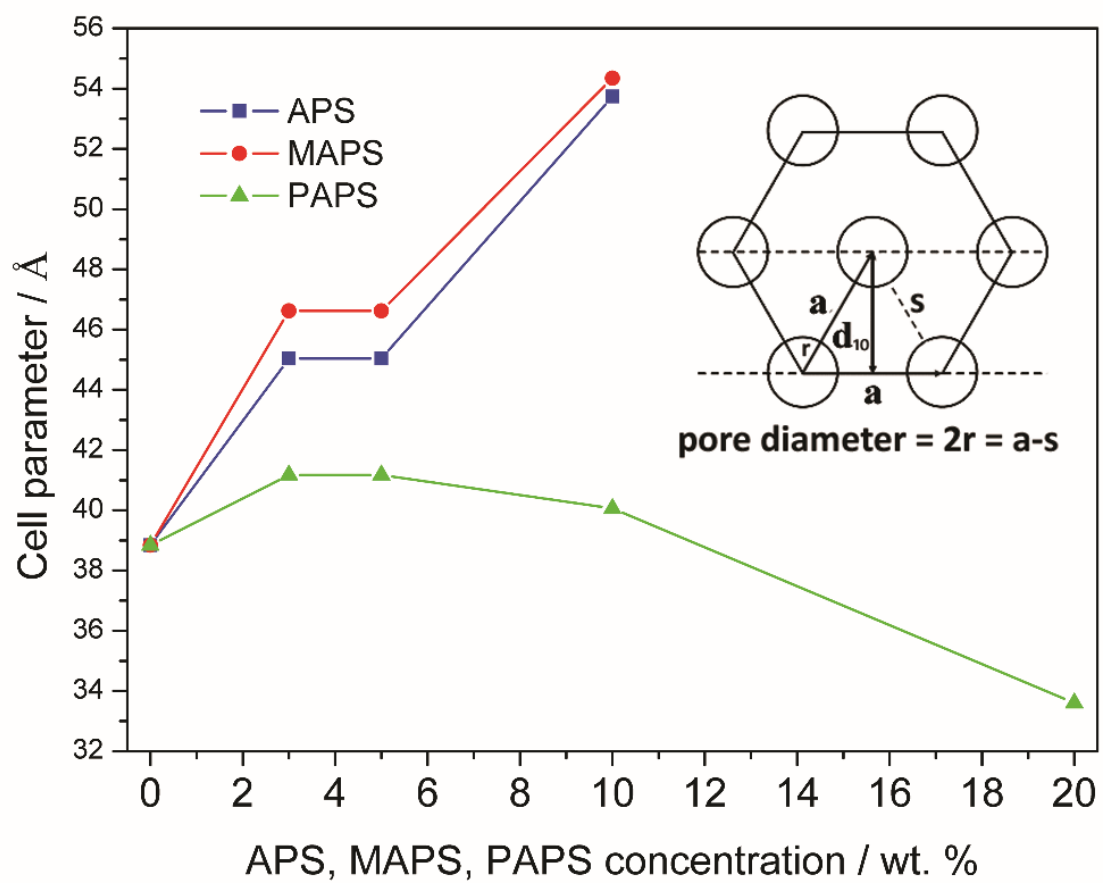

Figure 2. Change of the unit cell parameter in MCM41 silica modified with: APS - blue line; MAPS - red line; PAPS - green line. The inset: Definition of unit cell parameter (a), interplanar distance $\left(\mathrm{d}_{10}\right)$ and wall thickness (s) in the hexagonal mesoporous silica. Wall thickness can be calculated from unit cell parameter and pore width (see paragraph 3.3).

The PAP modified material showed the different behaviour. For the samples MCM413PAP and MCM41-5PAP, the shift of the (10) peak to the lower $q$ values was smaller in comparison with AP and MAP modified samples. For the samples MCM41-10PAP and MCM4120PAP, even opposite shifts of diffraction peaks, to higher $q$ values were observed, indicating a 
decrease in the unit cell parameter. Finally, for the material prepared by addition of $30 \mathrm{wt} \%$ PAPS, new peaks appeared in the SAXS pattern, indicating a hexagonal-to-lamellar phase transition.

The origin of this behaviour should be found in the nature of interactions established between the amino-organosiloxanes and CTAB as well as in the different hydrophilicity of the respective amine ligands. More specifically, during the one-pot synthesis, the amine $-\mathrm{NH}_{2}$ and $-\mathrm{NH}\left(\mathrm{CH}_{3}\right)$ group of APS and MAPS molecules, respectively, may interact with the polar $-\mathrm{N}^{+}\left(\mathrm{CH}_{3}\right)_{3}$ head of CTAB through hydrogen bonds, pull out the CTAB molecules, which increases the micelle diameter (see Fig. 3a). Consequently, at lower concentrations of APS and MAPS (3, 5, $10 \mathrm{wt} \%)$, the unit cell parameter of the materials increases as shown in Fig. 2. At higher concentrations of amines, the number of the interactions is so high that amines disrupt the packing of surfactants and weaken the micellar structure. The micelles are disorganized and no periodic porous structure is obtained (see Fig. 3a).

The situation is different with PAP ligand, which is highly hydrophobic. Planar molecule of phenyl ring may efficiently diffuse into the micellar interior. The swelling of the phenyl ring in the hydrophobic tails of the micelles does not disrupt the micelles like in APS and MAPS and has only little effect on the radius of the micelles at the concentration of PAPS 3, 5 and $10 \mathrm{wt} \%$. This is reflected only by a small change of the unit cell parameter in comparison with the sample MCM41 (see Fig. 2 and Fig. 3b). At the concentration of PAPS $20 \mathrm{wt} \%$, the more significant diffusion of the phenyl rings of PAPS into the micelles core causes their tighter packing and the contraction of the hydrophobic tails of the micelles (see Fig. 3b). Consequently, the unit cell parameter of the sample MCM41-20PAP is smaller in comparison with the sample MCM41 (see Fig. 2). At the concentration of PAPS of $30 \mathrm{wt} \%$, the PAP affects the packing arrangement of the surfactant molecules and forces the formation of a lamellar arrangement. Surfactant phase transformation from the hexagonal to lamellar is the result of the reduction of micellar curvature from cylindrical to a more elongated planar structure induced by the incorporation of phenyl ring molecules into the hydrophobic interior of micelles (see Fig. 3b). In contrast, because AP and MAP ligands may not be incorporated efficiently into the hydrophobic interior of the micelles, they interact with the polar headgroups and are therefore ineffective in causing mesophase modification from the hexagonal to lamellar. 


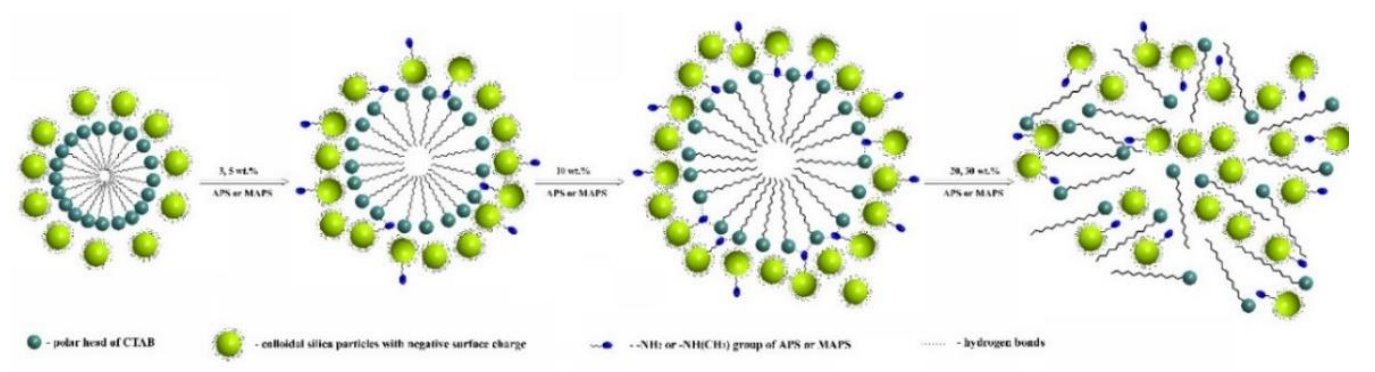

$\mathrm{a}$

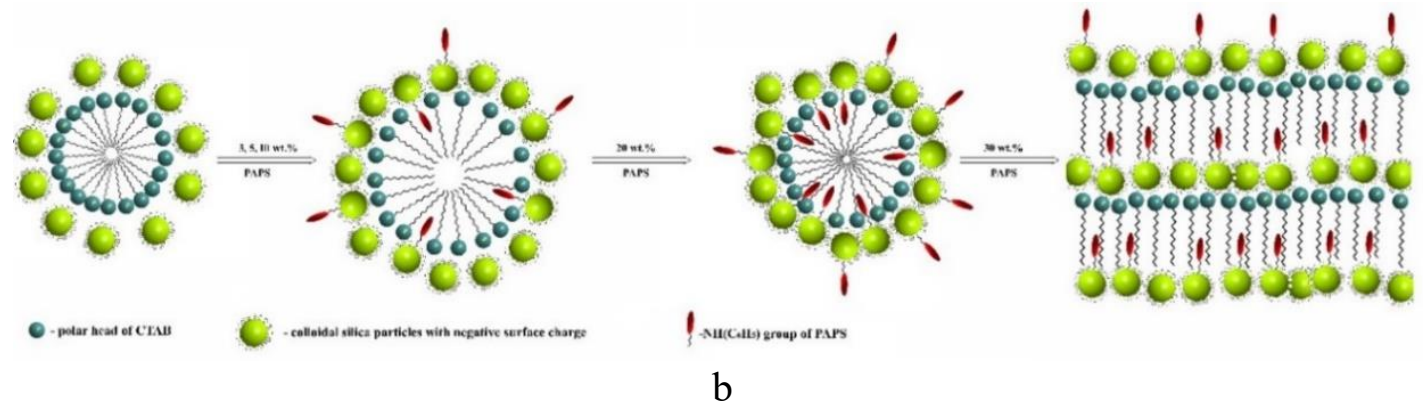

Figure 3. Proposed interactions of organosiloxanes with CTAB: a.) APS and MAPS; b.) PAPS.

\subsection{HRTEM micrographs}

The prepared samples were also studied using HRTEM. In Fig. 4, HRTEM images of unmodified MCM41 silica and samples modified with different amounts of the respective amines are shown. As it can be seen, the HRTEM micrographs well agree with the results suggested by SAXS measurements. The samples with the concentration of the APS, MAPS and PAPS of 3, 5 and $10 \mathrm{wt} \%$ in the synthesis gel show a regular porous structure with a hexagonal array of unimodal channels (see Fig. 4 a, b, c, d, g, h, i, 1, m, n). It should be noticed that the pores in the PAP modified sample MCM41-10PAP are not spherical but show triangular shape. This result confirms the above presented model supposing that, during the synthesis of PAP modified materials, the phenyl rings of PAP ligands may penetrate into hydrophobic interior of the micelles and slightly alter them. For the concentrations of amino-organosiloxanes 20 and $30 \mathrm{wt} \%$, the disordered or non-porous samples were obtained (see Fig. 4 e, f, j, k), which is in agreement with the SAXS data. We also note that the HRTEM image of sample MCM41-20MAP shows an amorphous phase with minor mesopores (see Fig. 4e). This agrees well with the SAXS pattern when no structure ordering is detected. However, some shoulder near the $q$ value of $0.131 \AA^{-1}$ indicate the presence of domains incorporating an ordered phase. The HRTEM micrograph of the sample MCM41-30PAP (Fig. 4p) was taken from as-synthesized sample, because, as mentioned above, upon template removal by solvent extraction, the sample dissolved, confirming its lamellar structure. 


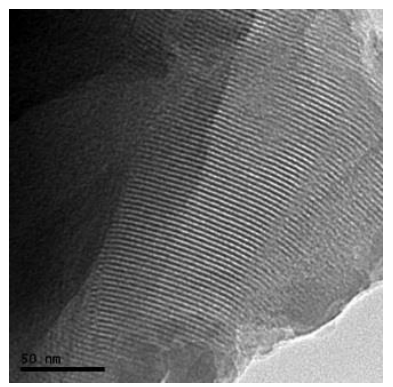

$a$

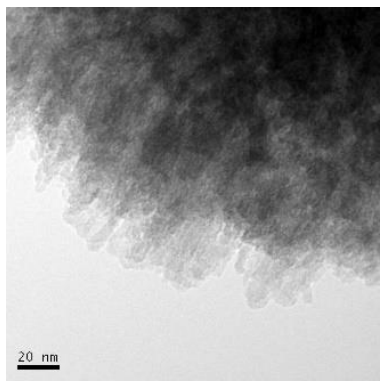

e

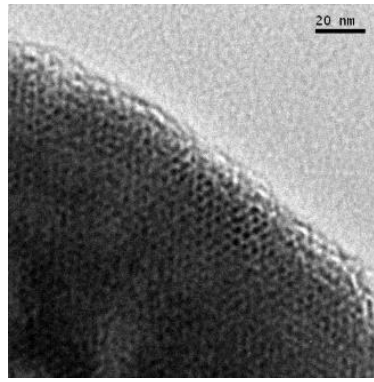

$i$

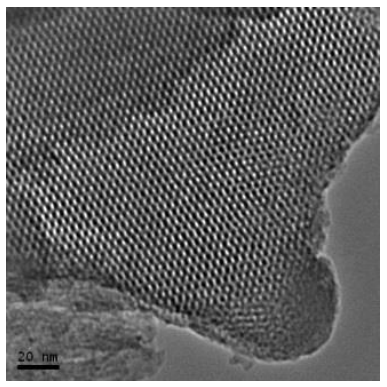

m

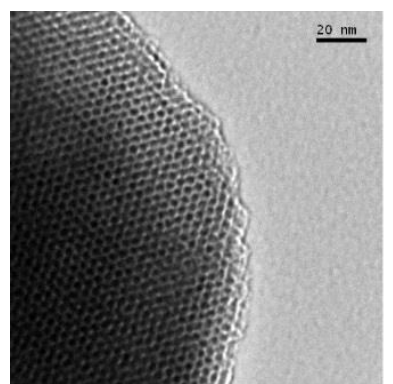

b

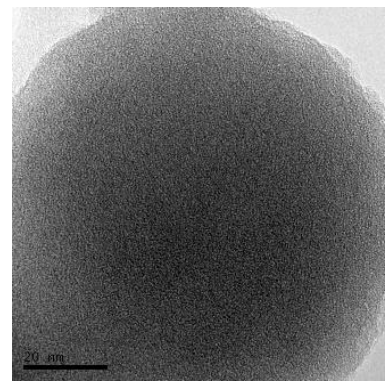

f

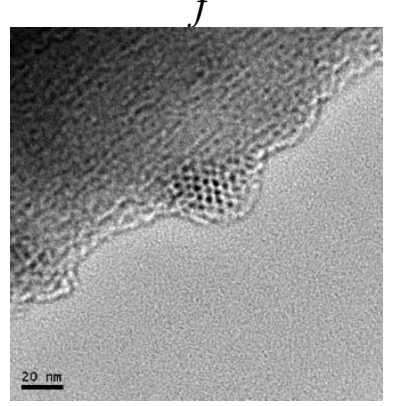

j

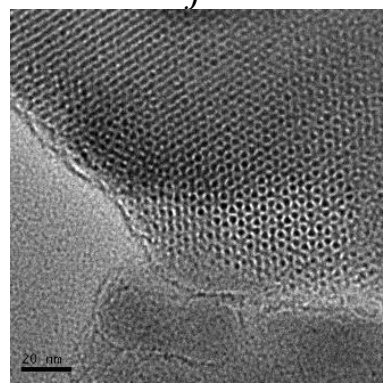

$n$

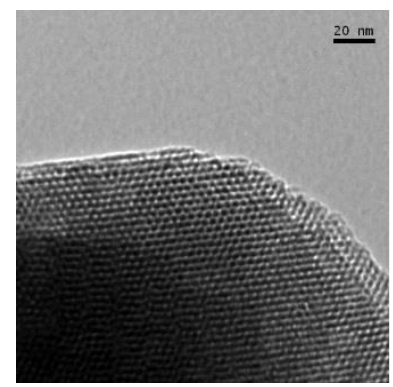

C

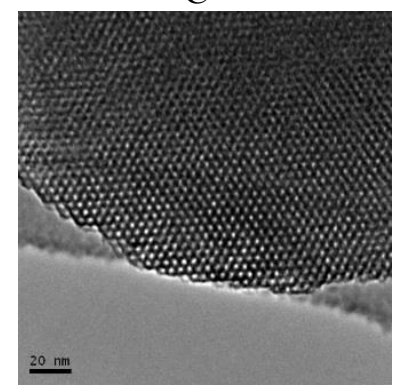

G

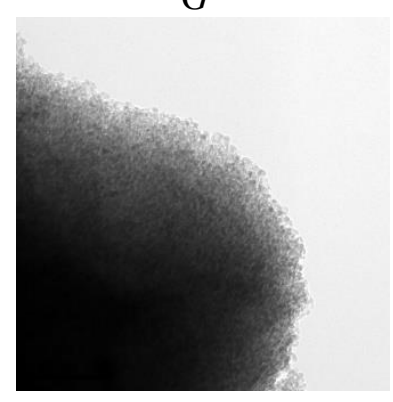

K

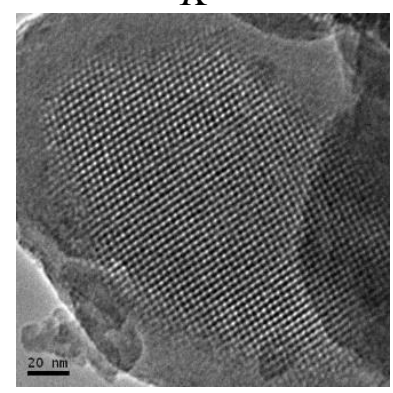

O

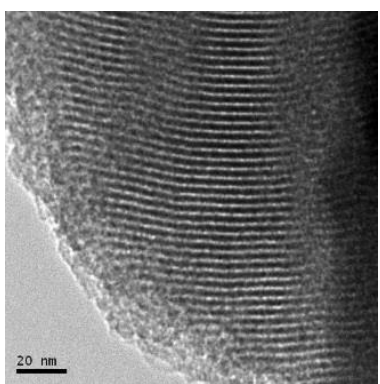

d

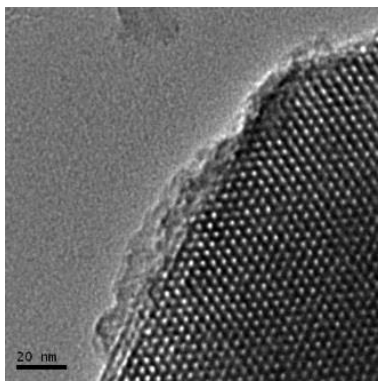

h

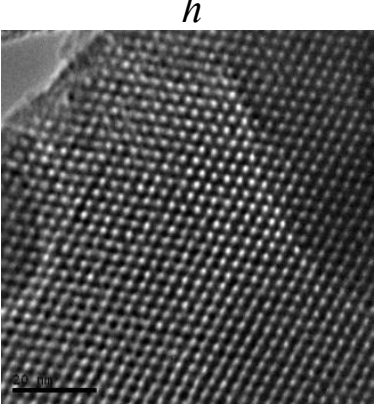

l

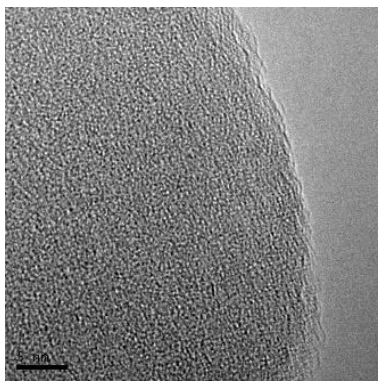

$p$

Figure 4. HRTEM micrographs of the samples a.) MCM41, b.) MCM41-3AP, c.) MCM41-5AP, d.) MCM41-10AP, e.) MCM41-20AP, f.) MCM41-30AP, g.) MCM41-3MAP, h.) MCM415MAP, i.) MCM41-10MAP, j.) MCM41-20MAP, k.) MCM41-30MAP, 1.) MCM41-3PAP, m.) MCM41-5PAP, n.) MCM41-10PAP, o.) MCM41-20PAP, p.) MCM41-30PAP. The samples a.)o.) are samples resulting after extraction of as-synthesised samples in ethanol. Sample p.) is as synthesised sample.

\subsection{Nitrogen adsorption/desorption}

Textural properties and porous structure of the prepared materials were further studied using nitrogen adsorption/desorption measurements at $77 \mathrm{~K}$ (see Fig. 5). The nitrogen 
adsorption/desorption isotherm of sample MCM-41 (see upper isotherm in Fig. 5 a-c) shows adsorption in micropores at low pressures, followed by an increase of the volume of adsorbed nitrogen at relative pressures $\mathrm{p} / \mathrm{p}_{0}=0.15-0.42$, arising from the capillary condensation of nitrogen in the mesopores.

The capillary condensation step is followed by a plateau indicating the filling of the mesopores. The shape of the isotherm of the sample MCM41 is of type IVc according to the IUPAC classification [36], without hysteresis and the coincidence of adsorption and desorption curve in the full range of the measurement. This isotherm confirms the presence uniform mesopores in the sample and it is consistent with MCM41 structure.

From the adsorption isotherm, we have calculated the specific surface area $\left(\mathrm{S}_{\mathrm{BET}}\right)$, the mesopore volume $\left(V_{p}\right)$ and pore diameter of the samples $\left(D_{p}\right)$ by the application of the BET equation and $\mathrm{BJH}$ method. The textural properties of the samples calculated from nitrogen adsorption/desorption measurements are given in Table 1. BET surface area of MCM-41 sample was $1068 \mathrm{~m}^{2} / \mathrm{g}$, pore diameter was about $27 \AA$ and pore volume $0.93 \mathrm{~cm}^{3} / \mathrm{g}$.

For the amine modified samples, the total adsorbed volume of nitrogen, pore size and specific surface area were found to decrease progressively upon functionalization, with increasing content of APS, MAPS and PAPS reagents in the synthesis gel. For the AP and MAP modified samples MCM41-xAP and MCM41-xMAP ( $\mathrm{x}=3,5,10 \mathrm{wt} \%$ ), the capillary condensation step was similar to unmodified MCM41, but shifted to slightly lower relative pressures due to the decrease of the pore size with increasing content of the amines (see Table 1).

For the MAP modified sample, the adsorption and desorption isotherms coincided similarly to the pristine MCM41 sample. However, for AP modified samples $(3,5,10 \mathrm{wt} \%)$ the hysteresis was observed, originating in secondary porosity. In AP modified samples, after extraction of the CTAB the secondary, irregular pores appeared, as shown in Fig. 6. Such type of H4 hysteresis loop is attributed to defects in the framework of MCM-41 [37]. This suggests differences in interactions between polar headgroups of CTAB and AP or MAP ligand respectively. 


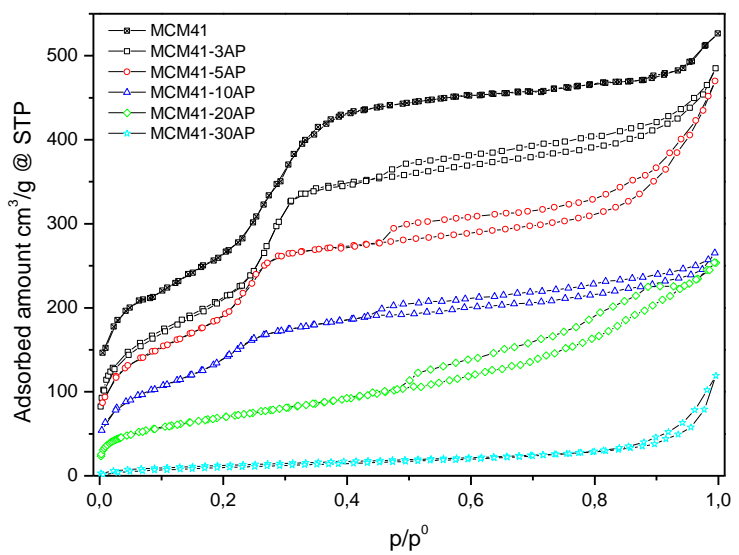

a

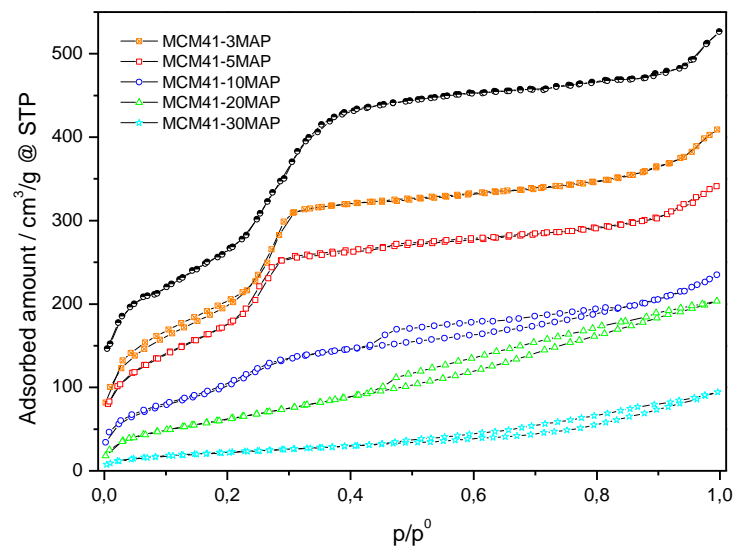

b

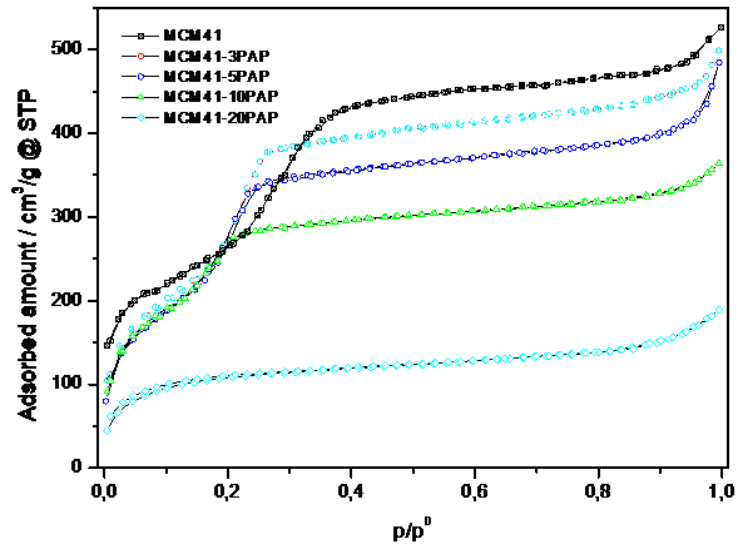

C

Figure 5. Nitrogen adsorption/desorption isotherms of the samples a.) MCM41-xAP, b.) MCM41xMAP, c.) MCM41-xPAP, where $\mathrm{x}=3,5,10,20,30$. 


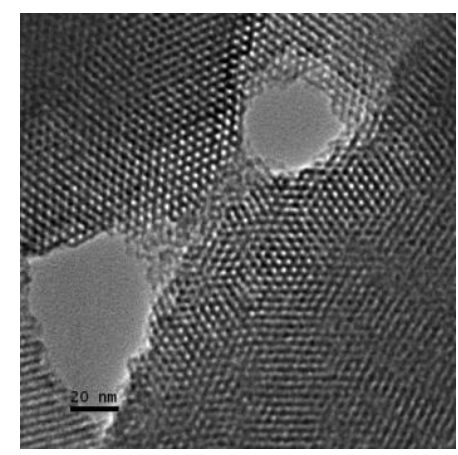

Figure 6. Secondary porosity observed in the samples modified by AP ligands after the template removal, leading to the hysteresis in the adsorption/desorption isotherms as shown in Fig. $4 \mathrm{a}$.

For the AP and MAP modified samples with concentrations of $20 \mathrm{wt} \%$ of APS and MAPS, the adsorption isotherms changed their shape and the regular mesoporosity in the sample was not identified. However, some microporosity was still present in the samples. For the AP and MAP modified samples containing $30 \mathrm{wt} \%$ of APS and MAPS, non-porous structures resulted, as indicated by adsorption isotherms.

The situation for PAP modified samples was different in comparison with the AP and MAP functionalized samples. Upon functionalization with PAPS, the capillary condensation step was better pronounced and steeper in comparison with unmodified MCM41 and AP and MAP modified samples. This indicates better ordering in the PAP modified samples and narrower pore size distribution, which can be explained by the presence of phenyl rings, which can act as a co-solvent in the synthesis gel. This is also supported by the fact that in PAP modified materials, the ordered porous structure was still present in the sample MCM41-20PAP, in contrast to samples MCM4120AP and MCM41-20MAP (see SAXS, HRTEM and nitrogen adsorption/desorption results).

However, for the MCM41-20PAP sample, the mesoporous adsorption step was not observed in the adsorption isotherm and the isotherm of the sample may be classified as Ib type according the IUPAC classification [36], typical for microporous materials with wider micropores. This observation is in good agreement with the calculated unit cell parameter, which is $33.6 \AA$ (see Table 1 and inset of Fig. 2). When we take into account that the wall thickness in MCM41 like materials is about $10 \AA$, the difference between the unit cell parameter and the wall thickness gives approximately the pore size (see inset of Fig. 2), which is about $23 \AA$. This well agrees with the shape of the adsorption isotherm of the sample MCM41-20PAP. 
Table 1. Textural and structural data of the prepared materials, accessed from SAXS and $\mathrm{N}_{2}$ adsorption/desorption experiments.

\begin{tabular}{|c|c|c|c|c|c|}
\hline Sample & $\begin{array}{l}\text { SBeT } \\
\mathrm{m}^{2} / \mathrm{g}\end{array}$ & $\begin{array}{l}\mathbf{D}_{\mathbf{p}} \\
\AA\end{array}$ & $\begin{array}{l}V_{p} \\
\mathrm{~cm}^{3} / \mathrm{g}\end{array}$ & $\begin{array}{l}\text { Unit cell } \\
\AA^{*}\end{array}$ & $\begin{array}{l}\text { Amine amount } \\
\mathrm{mmol} / \mathrm{g}^{* *}\end{array}$ \\
\hline MCM41 & 1068 & 26.8 & 0.930 & 38.84 & 0 \\
\hline MCM41-3AP & 798 & 24.5 & 0.797 & 45.04 & 0.95 \\
\hline MCM41-5AP & 686 & 23.5 & 0.668 & 45.04 & 1.64 \\
\hline MCM41-10AP & 449 & 22.3 & 0.620 & 53.74 & 2.48 \\
\hline MCM41-20AP & 257 & 8.6 & 0.225 & - & 3.60 \\
\hline MCM41-30AP & 47 & - & - & - & 3.80 \\
\hline MCM41-3MAP & 743 & 24.5 & 0.722 & 46.62 & 1.36 \\
\hline MCM41-5MAP & 652 & 23.5 & 0.566 & 46.62 & 1.71 \\
\hline MCM41-10MAP & 372 & 22.4 & 0.408 & 54.35 & 2.44 \\
\hline MCM41-20MAP & 176 & 8.1 & 0.136 & - & 3.11 \\
\hline MCM41-30MAP & 83 & - & 0.111 & - & 3.37 \\
\hline MCM41-3PAP & 1037 & 22.4 & 0.979 & 41.17 & 0.77 \\
\hline MCM41-5PAP & 889 & 21.3 & 0.816 & 41.17 & 0.96 \\
\hline MCM41-10PAP & 763 & 18.3 & 0.732 & 40.06 & 1.38 \\
\hline MCM41-20PAP & 374 & 9.4 & 0.198 & 33.6 & 2.06 \\
\hline
\end{tabular}

* see inset of Fig. 2

** from TGA data. See paragraph 3.5.

\subsection{Molecular simulation}

The formation of ordered mesoporous structures was further studied by molecular modelling using Monte Carlo simulation. To mimic the self-assembly of CTAB in the presence of hybrid organic-inorganic silica precursors, we applied an efficient coarse-grained lattice model that we have already employed in previous works where the self-assembly of block-copolymers at low and high concentrations was investigated [38-42]. The interested reader is referred to these works for further details on model and simulation methodology. Here, we only remind that the system is composed of four components: a surfactant, a pure silica precursor (TEOS), a hybrid 
precursor (APS, MAPS, or PAPS), and a water-like solvent. All components have been arranged in a fully occupied three dimensional lattice box and modelled as chains of connected sites, as shown in Fig. 7. The surfactant, denoted as $\mathrm{T}_{5} \mathrm{HH}_{3}$, was made up of a linear tail of five hydrophobic $T$ beads, and a bulky head of four hydrophilic $H$ beads. Such a bulky head favours the formation of spherical micelles and cylindrical aggregates similarly to what experimentally observed in the CTAB-templated synthesis of MCM-41 [2,3].

TEOS was modelled by a chain of two soluble beads, $I_{2}$, which establish strong interactions with the surfactant head. Finally, the three above mentioned amine-modified TEOSs (APS, MAPS, and PAPS) were modelled by adding to the $\mathrm{I}_{2}$ chain a given number of hydrophilic or hydrophobic beads accordingly to the chemical affinity of the organic substituents with the solvent. More specifically, the propyl chain was modelled by one single $T$ bead; the methyl and phenyl group of the secondary amines by one and three $T$ segments, respectively; and the $\mathrm{NH}$ or $\mathrm{NH}_{2}$ group by a single $H$ segment. Therefore, the primary amine (APS) was modelled by the linear chain $\mathrm{I}_{2} \mathrm{TH}$, the secondary amine with a methyl substituent (MAPS) by $\mathrm{I}_{2}$ THT, and the aromatic amine (PAPS) with $\mathrm{I}_{2} \mathrm{THT}_{3}$. The representations of the model silica precursors are shown in Fig. 7.

(a)

(e)

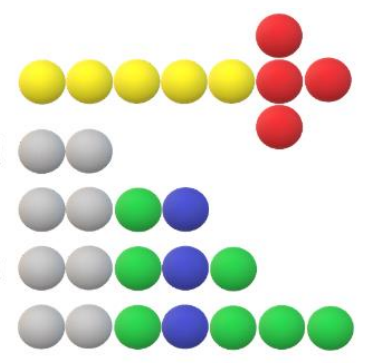

Figure 7. Coarse-grained model for surfactant and silica precursors. a.) $\mathrm{T}_{5} \mathrm{HH}_{3}$ as $\mathrm{CTAB}$; $b$ ) $\mathrm{I}_{2}$ as TEOS, c.) $\mathrm{I}_{2} \mathrm{TH}$ as APS, d.) $\mathrm{I}_{2} \mathrm{THT}$ as MAPS and e.) $\mathrm{I}_{2} \mathrm{THT}_{3}$ as PAPS. Yellow and red beads represent the surfactant tail and head, respectively, while the gray bead represent the inorganic precursor. Hydrophilic and hydrophobic beads of the hybrid precursors are shown in blue and green, respectively.

To study the phase behaviour of amphiphilic systems containing pure silica and a hybrid precursor, we added amine-modified TEOS of the types given in Fig. 7, solvent and surfactant in three dimensional lattice box with periodic boundaries. In general, a phase separation between a solvent-rich phase, containing mostly solvent and a small number of precursors, and an hexagonally-packed surfactant-rich phase, were detected. This ordered arrangement is observed 
for low-to-moderate concentrations of hybrid precursors (up to $20 \%$ by volume for $\mathrm{I}_{2} \mathrm{THT}$, less for the others, in a system containing $40 \%$ by volume of $\mathrm{T}_{5} \mathrm{HH}_{3}$ ), but is then destroyed or transformed into lamellar structures at increasing concentration of the hybrid precursors. Images obtained during the simulations showing the phase separation between a solvent-rich phase and a surfactant rich phase are given in Fig. 8.

The phase separation is generated by the strongly attractive interactions between the inorganic moiety and the surfactant heads. By contrast, the repulsive interactions between the inorganic beads and the surfactant tails determine the location of the inorganic precursor around the cylindrical aggregates. Most of the hybrid precursors are incorporated in the framework, whereas some of the more hydrophilic hybrid precursors $\left(\mathrm{I}_{2} \mathrm{TH}\right.$ and $\left.\mathrm{I}_{2} \mathrm{THT}\right)$ are present in the solvent rich phase.
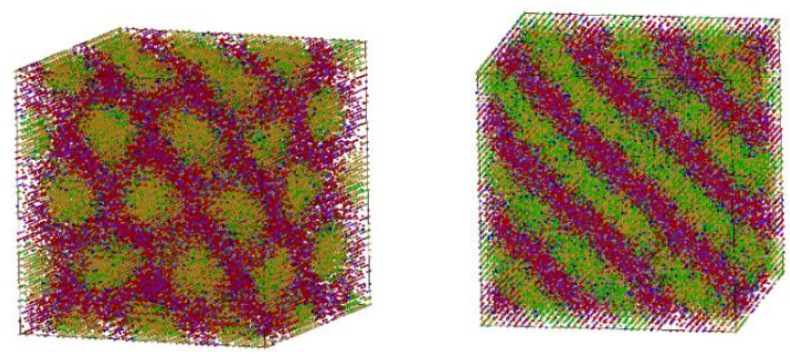

Figure 8. Representative hexagonal (right) and lamellar (left) structures obtained during the simulations of systems containing $40 \%$ of $\mathrm{T}_{5} \mathrm{HH}_{3}, 10 \% \mathrm{I}_{2}$, and $10 \% \mathrm{I}_{2} \mathrm{THT}_{3}$ (left) or $25 \% \mathrm{I}_{2} \mathrm{THT}_{3}$ (right). Surfactant heads and tails are shown in red and yellow, respectively; the inorganic part of the precursors in gray; $H$ and $T$ segments belonging to $\mathrm{I}_{2} \mathrm{THT}_{3}$ are shown in blue and green, respectively. The solvent is not shown. All percentages represent volume fractions.

At $10 \%$ of $\mathrm{I}_{2}$, the highest concentrations at which hexagonally-packed morphologies have been found are $13 \%$ for $\mathrm{I}_{2} \mathrm{TH}, 15 \%$ for $\mathrm{I}_{2} \mathrm{THT}$, and $20 \%$ for $\mathrm{I}_{2} \mathrm{THT}_{3}$. In particular, in systems with $\mathrm{I}_{2} \mathrm{TH}$ or $\mathrm{I}_{2} \mathrm{THT}$, no other ordered phases have been noticed, whereas in those containing between $18 \%$ and $25 \%$ of $\mathrm{I}_{2} \mathrm{THT}_{3}$, we detected lamellar phases in equilibrium with a very dilute solventrich phase. In this case, the surfactant concentration in the ordered phase is slightly less than $50 \%$, much lower than that generally required to form lamellar phases in binary $\mathrm{T}_{5} \mathrm{HH}_{3} /$ solvent systems [40]. We therefore conclude that the hybrid precursor $\mathrm{I}_{2} \mathrm{THT}_{3}$ determines the swelling the hydrophobic regions resulting from the surfactant aggregation and causes the transition to lamellar phases as experimentally observed here and previously with long-chain amines or alcohols [43]. 


\subsection{Thermal stability and ligand concentration}

The thermal stability of the samples and amine concentration was accessed by thermogravimetric analysis. Fig. 9 shows representative TG/DTA curves of MCM41-5AP, MCM41-5MAP and MCM41-5PAP samples during heating in air. The mass loss between room temperature and $150{ }^{\circ} \mathrm{C}$ corresponds to liberation of water/ethanol remained in the pores from the extraction. The solvent removal was accompanied by endothermic effects at about $90{ }^{\circ} \mathrm{C}$. It is obvious that mass loss in this temperature range reflected the hydrophobic character of the PAP ligand. For the sample MCM41-5PAP, containing the phenyl ring, the lowest mass loss was observed. The mass loss up to $150{ }^{\circ} \mathrm{C}$ was $5.7 \%$ for the sample MCM41-5AP, 9.4\% for the sample MCM41-5MAP, and 2.7\% for the sample MCM41-5PAP. On further heating the pyrolysis of amine ligands took place and the decomposition was complete by $800{ }^{\circ} \mathrm{C}$. The process of decomposition in the range $150-800{ }^{\circ} \mathrm{C}$ was divided in two poorly separated steps and it was accompanied by exothermic peaks on DTA at 348 and $581{ }^{\circ} \mathrm{C}$ for the sample MCM41-5AP, 336 and $492{ }^{\circ} \mathrm{C}$ for the sample MCM41-5MAP and 358, 494 and $618^{\circ} \mathrm{C}$ for the sample MCM41-5PAP.

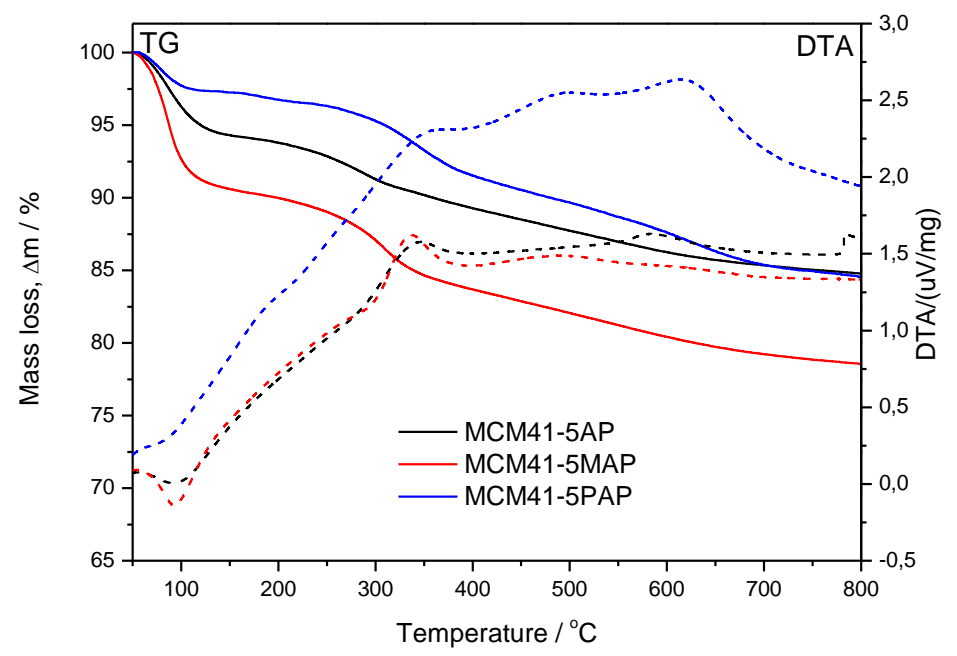

Figure 9. TG/DTA curves of the thermal decomposition of the samples MCM41-5AP, MCM415MAP and MCM41-5PAP.

The amount of the amines in the samples progressively increased with the concentration of the respective amino-organosiloxanes (APS, MAPS and PAPS, respectively) in the synthesis gel. The thermogravimetric curves showed higher mass loss with the increasing concentration of amines. As an example, the comparison of MAP modified samples MCM41-xMAP (x = 3, 5, 10, 
20, 30) is shown in Fig. 10a. The comparison of the mass losses for all the prepared samples is shown in Fig. 10b. It is obvious that different mass losses were observed for AP, MAP and PAP modified samples, which reflect the different molar masses of the respective amine ligands. From the observed mass losses, we could calculate the concentration of the amines (mmol of amine per gram of the sample) in the respective samples. The results are summarised in Table 1.
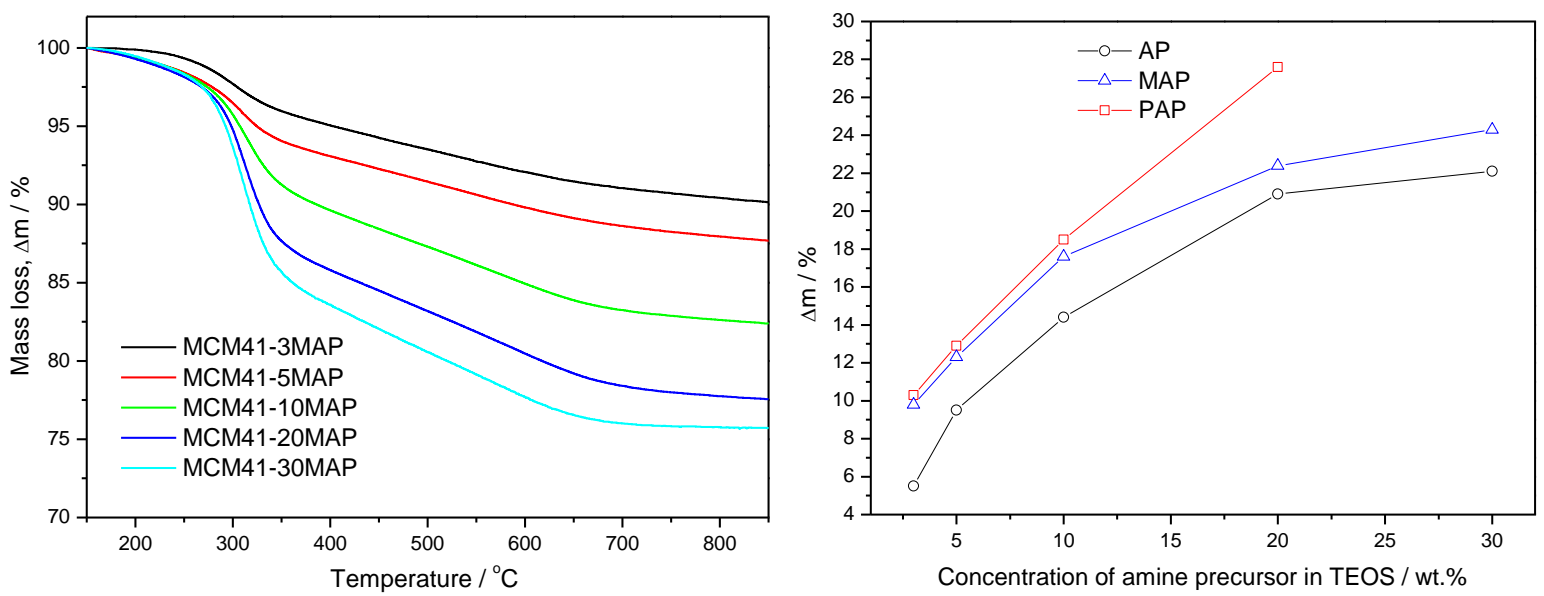

Figure 10. a.) Normalized thermogravimetric curves of the samples MCM41-xMAP in the temperature range $150-850{ }^{\circ} \mathrm{C}$, where $\mathrm{x}=3,5,10,20,30$. b.) Graphs showing the observed mass losses during the thermal decomposition of the AP, MAP and PAP ligands in the respective samples.

\section{6. $\mathrm{CO}_{2}$ adsorption}

The $\mathrm{CO}_{2}$ uptake was measured gravimetrically. Before the adsorption, the samples were first activated by heating to $110^{\circ} \mathrm{C}$ in nitrogen and then cooled down to $25^{\circ} \mathrm{C}$. After the activation, during the sorption experiments, the samples were purged with $\mathrm{CO}_{2} / \mathrm{N}_{2}$ certified gas mixture, containing $10 \%$ of carbon dioxide, which composition resembles the concentration of $\mathrm{CO}_{2}$ in the flue gas, where concentration is ranging from $10 \%$ to $15 \%$ [35]. For illustration, Fig. 11 shows three carbon dioxide adsorption/desorption cycles on MCM41-10AP, MCM41-10MAP and MCM41-10PAP samples. Upon introduction of carbon dioxide, a rapid weight gain was observed due to $\mathrm{CO}_{2}$ capture by amine active sites of modified samples (see the area denoted with "a" in Fig. 11a). After the saturation of amine active sites, no further adsorption and plateau were observed on the adsorption curve (see the area denoted with "b" in Fig. 11a). The regeneration of the sample was performed by heating it up to $70{ }^{\circ} \mathrm{C}$ in nitrogen atmosphere, which led to the 
removal of $\mathrm{CO}_{2}$ and mass decrease (see the area denoted with "c" in Fig. 11a). The adsorption of carbon dioxide was accompanied by evolution of heat as reflected by exothermic effect on DTA curves (see Fig. 11a-c). The regeneration of the sorbent and desorption of carbon dioxide was accompanied on the DSC curves by endothermic effects.

The $\mathrm{CO}_{2}$ adsorption capacity of the samples shown in Fig. 11 increases in the order MCM41-10PAP $(0.54 \mathrm{mmol} / \mathrm{g})<\mathrm{MCM} 41-10 \mathrm{MAP}(0.65 \mathrm{mmol} / \mathrm{g})<\mathrm{MCM} 41-10 A P(0.67$ $\mathrm{mmol} / \mathrm{g}$ ). The increase of the adsorption capacity in this order agrees with our previous work, where we showed that adsorption of carbon dioxide over AP, MAP and PAP ligands is driven by amine basicity [32]. Basicity of AP and MAP ligands is higher than the basicity of PAP ligand, showing the lowest $\mathrm{CO}_{2}$ uptake. This behaviour was further expressed by the DSC curves. For the PAP modified sample, with lowest basicity, the exo- and endothermic effects on the DSC, associated with adsorption and desorption of carbon dioxide, are lower than for AP and MAP modified samples.

The comparison of the adsorption capacities of all the studied samples is shown in Fig. 12. As we can see, the adsorption capacity of the samples increases with increasing concentration of AP, MAP and PAP ligands. It is surprising that the adsorption capacity increased also in the samples containing 20 and $30 \mathrm{wt} \%$ of respective ligands, which show much lover surface area and pore volume as compared to the samples containing 3,5 and $10 \mathrm{wt} \%$ (see Table 1). This reflects the fact that adsorption of carbon dioxide over amine modified silica materials is not driven by physisorption (textural characteristics - surface area, pore volume), but it is a chemisorption reaction with adsorption heats in the range $50-100 \mathrm{~kJ} / \mathrm{mol}$ ) [34].

The adsorption of carbon dioxide in amine modified silicas under anhydrous conditions is governed by Dankwerts' mechanism [44], when one mole of carbon dioxide reacts with two moles of amine and the reaction can be expressed as

$$
\mathrm{CO}_{2}+2 \mathrm{R}_{1} \mathrm{R}_{2} \mathrm{NH} \rightarrow \mathrm{R}_{1} \mathrm{R}_{2} \mathrm{NH}_{2}{ }^{+}+\mathrm{R}_{1} \mathrm{R}_{2} \mathrm{NCO}_{2}{ }^{-}
$$

where $\mathrm{R} 1=-\mathrm{H}$ for primary mines, $\mathrm{R} 1, \mathrm{R} 2=$ alkyl/aryl for secondary amines. 


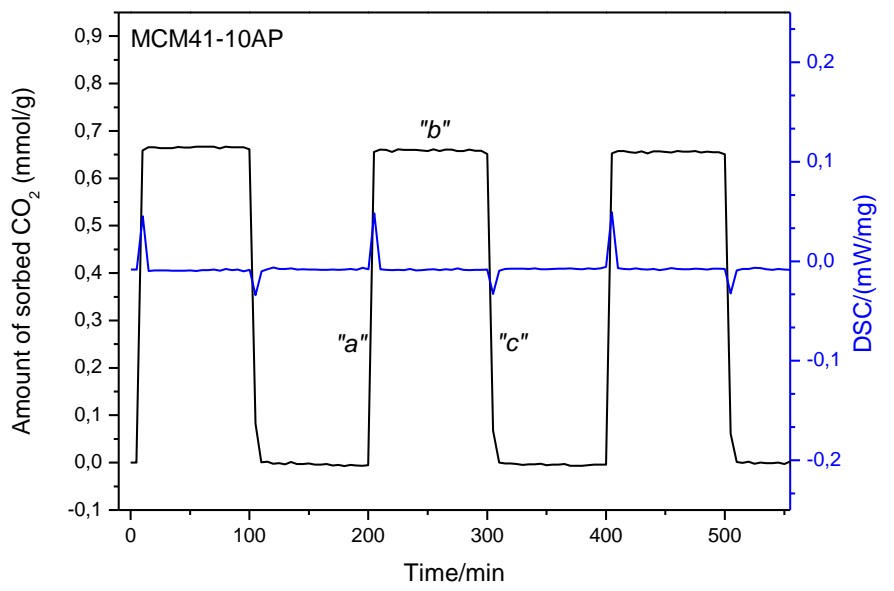

$\mathrm{a}$

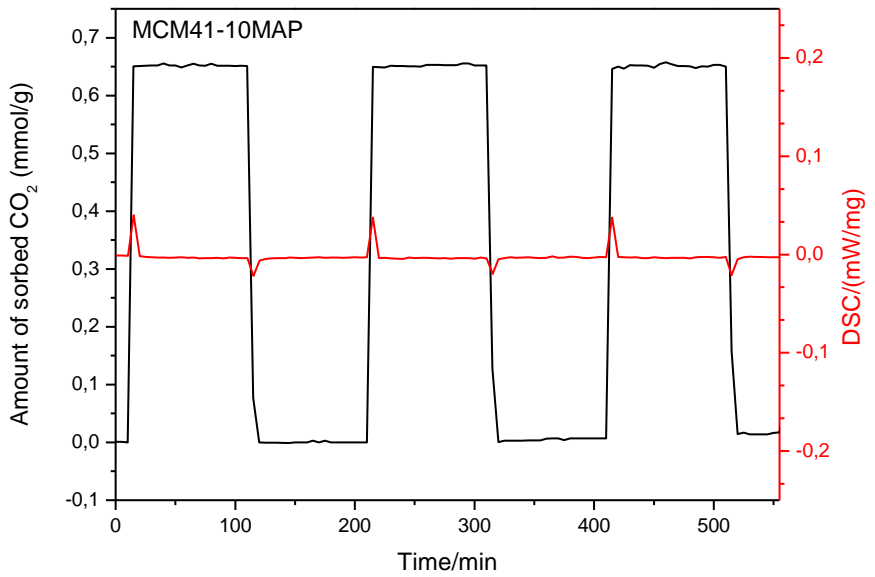

b

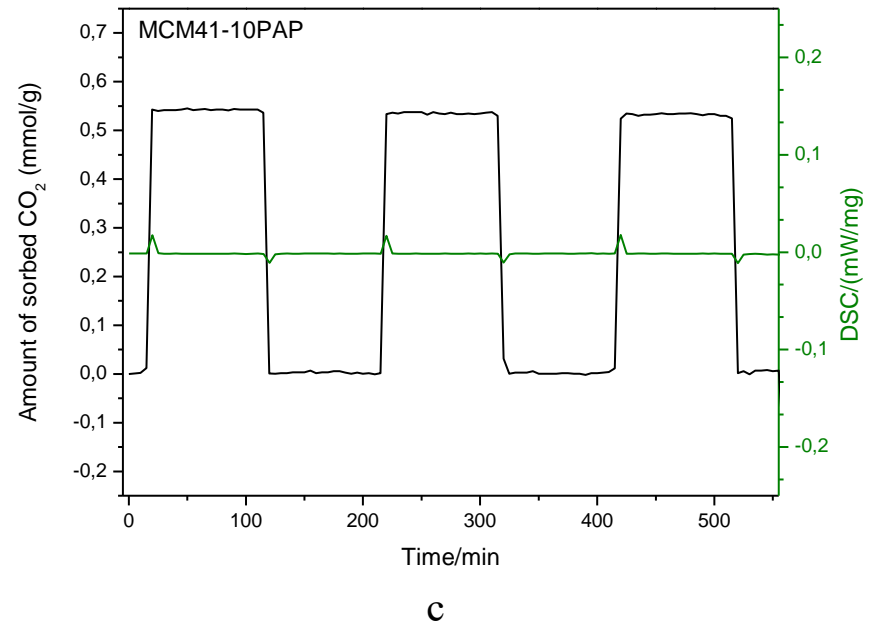

Figure 11. Carbon dioxide adsorption on the samples MCM41-10AP, MCM41-10MAP and MCM41-10PAP. 
Therefore, from the known amount of the amine ligands (see Table 1), we can calculate the theoretical uptake of carbon dioxide by respective samples and to compare it with the experimentally observed values. We can define the efficiency of the samples as the ratio $\eta=$ (experimental $\mathrm{CO}_{2}$ uptake)/(theoretical $\mathrm{CO}_{2}$ uptake). The results are presented in Fig.12. It can be seen that while for lower concentration of amines $(3,5,10 \mathrm{wt} \%)$ the experimental uptake approaches to theoretical values. However, by increasing concentration of amines, the differences between theoretical and experimental values increase. For the concentrations of respective amines 20 and $30 \mathrm{wt} \%$, the efficiency is lower than $50 \%$. It also suggests that while the $\mathrm{CO}_{2}$ uptake increases with the content of amines, and non-porous samples containing 20 and $30 \mathrm{wt} \%$ of amines show the highest uptake, their efficiency is lower. This is most likely due to the inaccessibility of some amine groups in these samples, when the samples changed from highly porous to non-porous particles. This is also confirmed by the fact that while the amine loading in the prepared samples MCM41-20Y and MCM41-30Y ( $\mathrm{Y}=\mathrm{AP}, \mathrm{MAP}, \mathrm{PAP})$ is 3.60 and $3.80 \mathrm{mmol} / \mathrm{g}$ for MCM41-20AP and MCM41-30AP, 3.11 and $3.37 \mathrm{mmol} / \mathrm{g}$ for MCM41-20MAP and MCM41-30MAP and 2.06 $\mathrm{mmol} / \mathrm{g}$ for MCM41-20PAP (see Table 1) are higher than in samples prepared in our previous study by grafting $(2.13,2.16$ and $1.56 \mathrm{mmol} / \mathrm{g}$ for AP, MAP and PAP modified samples, respectively) [32], the sorption capacities and amine efficiencies for materials prepared by cocondensation are lower.

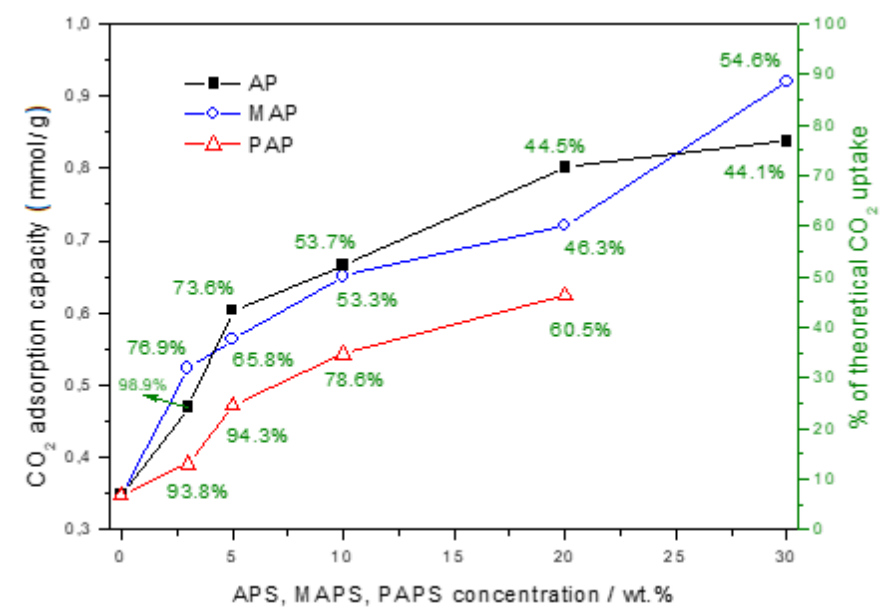

Figure 12. Carbon dioxide adsorption capacity (left y-axis, $\mathrm{mmol} / \mathrm{g}$ ) and efficiency (right y-axis, $\%)$ of the studied samples. 


\section{Conclusions}

In summary, APS, MAPS, and PAPS modified silica materials were prepared by direct cocondensation of TEOS and respective amino-organoalkoxysilanes. The well-ordered nanoporous materials were prepared in low concentrations of amino-organosiloxanes in the synthesis gel. The unit cell parameter of the hexagonally ordered amino-functionalized MCM41 samples is strongly dependent on the content of amino-organoalkoxysilanes, their type and size, suggesting that the interaction between the more hydrophilic (AP, MAP) and hydrophobic (PAP) amino-organic fragment and the hydrophilic head/hydrophobic tail region of the surfactant strongly influences the formation of the silica micelle composites. The long-range ordering of nanoporous structure of the APS and MAPS modified materials decreased with the increase of the concentration of aminoorganoalkoxysilanes in the initial mixture. For PAP modified materials, the ordered structures were observed at all used concentrations, but at the highest used concentration, $30 \mathrm{wt} \%$, the micelles cannot accommodate large amounts of PAP and phase change from the hexagonal to lamellar was observed. Our simulation results were key to understand the origin of this behaviour. More specifically, if the functional group of the silica precursor is especially hydrophobic (PAP modified TEOS), it is able to swell the hydrophobic core of the hexagonally-packed cylindrical aggregates and promote the formation of lamellar structures. By contrast, if the hydrophobicity of the functional group is less pronounced, the change in the interfacial properties will provoke the destruction of the hexagonal arrangement and the formation of a disordered phase. The study of carbon dioxide adsorption over prepared materials showed that the adsorption of carbon dioxide over AP, MAP and PAP ligands is driven by amine basicity. However, observed adsorption capacities and amine efficiencies were lower than observed for similar materials prepared by grafting. This suggests that in materials prepared by one-pot synthesis some amine active centers are inaccessible for carbon dioxide.

\section{Acknowledgements}

This work was supported by the Slovak Research and Development Agency under the contract APVV-15-0520 and by the Scientific Grant Agency of the Slovak Republic (VEGA) project no. 1/0745/17. The authors thank the Ministry of Education, Science, Research and Sport of the Slovak Republic and Accreditation Commission of the Slovak Republic for the financial support of the TRIANGEL team in the frame of the scheme Top Research Teams in Slovakia. AP and FRS 
acknowledge funding from the European Union's Horizon 2020 research and innovation programme under the Marie Skłodowska-Curie grant agreement No 676045 (MULTIMAT).

\section{References}

1. Ch. Park, J. Yoon, E.L. Thomas, Enabling nanotechnology with self assembled block copolymer patterns, Polymer 44 (2003) 6725-6760.

2. A. Firouzi, F. Atef, A.G. Oertli, G.D. Stucky, B.F. Chmelka, Alkaline lyotropic silicatesurfactant liquid crystals, J. Am. Chem. Soc. 119 (1997) 3596-3610

3. J.S. Beck, J.C. Vartuli, W.J. Roth, M.E. Leonowicz, C.T. Kresge, K.D. Schmitt, C.T.W. Chu, D.H. Olson, E.W. Sheppard, S.B. McCullen, J.B. Higgins, J.L. Schlenker, A new family of mesoporous molecular sieves prepared with liquid crystal templates, J. Am. Chem. Soc. 114 (1992) 10834-10843.

4. C.T. Kresge, M.E. Leonowicz, W.J. Roth, C.T. Vartuli, J.S. Beck, Ordered mesoporous molecular sieves synthesized by a liquid-crystal template mechanism, Nature 359 (1992) 710-712.

5. I. Diaz, J. Perez-Pariente, O. Terasaki, Structural study by transmission and scanning electron microscopy of the time-dependent structural change in M41S mesoporous silica (MCM-41 to MCM-48, and MCM-50), J. Mater. Chem. 14 (2004) 48-53.

6. D. Halamová, M. Badaničová, V. Zeleňák, T. Gondová, U. Vainio, Naproxen drug delivery using periodic mesoporous silica SBA-15, Appl. Surf. Sci. 256 (2010) 6489-6494.

7. M. Etienne, B. Lebeau, A. Walcarius, Organically-modified mesoporous silica spheres with MCM-41 architecture, New J. Chem. 26 (2002) 384-386.

8. A. Walcarius, C. Despas, J. Bessiere, Molecular sieving with amorphous monodisperse silica beads, Micropor. Mesopor. Mater. 23 (1998) 309-313.

9. M.H. Lim, A. Stein, Comparative studies of grafting and direct syntheses of inorganicorganic hybrid mesoporous materials, Chem. Mater. 11 (1999) 3285-3295.

10. A.S.M. Chong, X.S. Zhao, A.T. Kustedjo, S.Z. Qiao, Functionalization of large-pore mesoporous silicas with organosilanes by direct synthesis, Micropor. Mesopor. Mater. 72 (2004) 33-42.

11. A. Stein, B.J. Melde, R.C. Schroden, Hybrid inorganic-organic mesoporous silicates nanoscopic reactors coming of age, Adv. Mater. 12 (2000) 1403-1419. 
12. T. Deschner, Y.C. Liang, R. Anwander, Silylation efficiency of chorosilanes, alkoxysilanes and monosilazanes on periodic mesoporous silica, J. Phys. Chem. C 114 (2010) 2260322609.

13. L. Mercier, T.J. Pinnavaia, Direct synthesis of hybrid organic-inorganic nanoporous silica by a neutral amine assembly route: structure-function control by stoichiometric incorporation of organosiloxane molecules, Chem. Mater. 12 (2000) 188-196.

14. X. Wang, X- Du, Ch. Li, X. Cao, Direct synthesis and characterization of phenylfunctionalized SBA-15, Appl. Surf. Sci. 254 (2008) 3753-3757.

15. J. Brown, L. Mercier, T.J. Pinnavaia, Selective adsorption of $\mathrm{Hg}^{2+}$ by thiol-functionalized nanoporous silica, Chem. Commun. 1999, 69-70.

16. L. Zhu, X. Liu, T. Chen, Z. Xu, W. Yan, H. Zhang, Functionalized periodic mesoporous organosilicas for selective adsorption of proteins, Appl. Surf. Sci., 258 (2012) 7126-7134.

17. J.A. Melero, G.D. Stucky, R. van Grieken, G. Morales, Direct syntheses of ordered SBA15 mesoporous materials containing arenesulfonic acid groups, J. Mater. Chem. 12 (2002) 1664-1670.

18. J.Y. Choi, C.H. Kim, K.D. Kim, Formation and characterization of monodisperse, spherical organo-silica powders from organo-alkoxysilane-water system, J. Am. Ceram. Soc. 81 (1998) 1184-1188.

19. A. Sayari, Y. Belmabkhout, R. Serna-Guerrero, Flue gas treatment via $\mathrm{CO}_{2}$ adsorption, Chem. Eng. J. 171 (2011) 760-774.

20. A. Samanta, A. Zhao, G.K.H. Shimizu, P. Sarkar, R. Gupta, Post-combustion $\mathrm{CO}_{2}$ capture using solid sorbents: A review, Ind. Eng. Chem. Res. 54 (2011) 1438-1463.

21. T.C. Drage, C.E. Snape, L.A. Stevens, J. Wood, J. Wang, A.I. Cooper, R. Dawson, X. Guo, C. Satterley, R.J. Irons, Materials challenges for the development of solid. sorbents for post-combustion carbon capture, J. Mater. Chem. 22 (2012) 2815-2823.

22. G.P. Knowles, S.W. Delaney, A.I. Chaffee, Diethylenetriamine[propyl(silyl)]functionalized (DT) mesoporous silicas as $\mathrm{CO}_{2}$ adsorbents, Ind. Eng. Chem. Res. 45 (2006) 2626-2633.

23. L. Wang, M. Yao, X. Hu, G. Hu, J. Lu, M. Luo, M. Fan, Amine-modified ordered mesoporous silica: The effect of pore size on $\mathrm{CO}_{2}$ capture performance, Appl. Surf. Sci. 324 (2015) 286-292. 
24. P.J.E. Harlick, A. Sayari, Applications of pore-expanded mesoporous silica. 5. Triamine grafted material with exceptional $\mathrm{CO}_{2}$ dynamic and equilibrium adsorption performance, Ind. Eng. Chem. Res. 46 (2007) 446-458.

25. J.C. Hicks, J.H. Drese, D.J. Fauth, M.L. Gray, G. Qi, C.W. Jones, Designing adsorbents for $\mathrm{CO}_{2}$ capture from flue gas-hyperbranched aminosilicas capable of capturing $\mathrm{CO}_{2}$ reversibly, J. Am. Chem. Soc. 130 (2008) 2902-2903.

26. Y. Belmabkhout, A. Sayari, Isothermal versus non-isothermal adsorption-desorption cycling of triamine-grafted pore-expanded MCM-41 mesoporous silica for $\mathrm{CO}_{2}$ capture from flue gas, Energ. Fuel 24 (2010) 5273 - 5280.

27. S. Choi, J.H. Drese, P.M. Eisenberger, C.W. Jones, Application of amine-tethered solid sorbents for direct $\mathrm{CO}_{2}$ capture from the ambient air, Environ. Sci. Technol. 45 (2011) 2420-2427.

28. D.D. Miller, S.S.C. Chuang, Control of $\mathrm{CO}_{2}$ adsorption and desorption using polyethylene glycol in a tetraethylenepentamine thin film: an in situ ATR and theoretical study, J. Phys. Chem. C 120 (2016) 25489-25504.

29. A. Sayari, A. Heydari-Gorji, Y. Yang, $\mathrm{CO}_{2}$-induced degradation of amine-containing adsorbents: reaction products and pathways, J. Am. Chem. Soc. 134 (2012) 13834-13842.

30. Y. Gun, K. Seung, S.S. Shin, U.S. Choi, Primary, Secondary and tertiary amines for $\mathrm{CO}_{2}$ capture: Designing for mesoporous $\mathrm{CO}_{2}$ adsorbents, J. Colloid Interf. Sci. 361 (2011) 594602.

31. C. Knofel, J. Descarpentries, A. Benzaouia, V. Zeleňák, S. Mornet, P.L. Llewellyn, V. Hornebecq, Functionalised micro/mesoporous silica for the adsorption of carbon dioxide, Micropor. Mesopor. Mater. 99 (2007) 79-85.

32. V. Zeleňák, D. Halamová, L. Gaberová, E. Bloch, P. Llewellyn, Amine-modified SBA-12 mesoporous silica for carbon dioxide capture: Effect of amine basicity on sorption properties, Micropor. Mesopor. Mater. 116 (2008) 358-364.

33. V. Zeleňák, M. Badaničová, D. Halamová, J. Čejka, A. Zukal, N. Murafa, G. Goerigk, Amine-modified ordered mesoporous silica: Effect of pore size on carbon dioxide capture, Chem. Eng. J. 114 (2008) 336-342. 
34. V. Zeleňák, M. Skř́nska, A. Zukal, J. Čejka, Carbon dioxide adsorption over amine modified silica: Effect of amine basicity and entropy factor on isosteric heats of adsorption, Chem. Eng. J. 348 (2018) 327 - 337.

35. R.A. Khatri, S.S.C. Chuang, Y. Soong, M. Gray, Carbon dioxide capture by diaminegrafted SBA-15: A combined Fourier transform infrared and mass spectrometry study, Ind. Eng. Chem. Res. 44 (2005) 3702-3708.

36. M. Thommes, K. Kaneko, A.V. Neimark, J.P. Olivier, F. Rodriguez-Reinoso, J. Rouquerol, K.S.W. Sing, Physisorption of gases, with special reference to the evaluation of surface area and pore size distribution (IUPAC technical report), Pure Appl. Chem. 87 (2015) 1051-1069.

37. H.-P. Lin, S.-T. Wong, Ch.-Y. Mou, Ch.-Y. Tang, Extensive void defects in mesoporous aluminosilicate MCM-41, J. Phys. Chem. B 104 (2000) 8967-8975.

38. A. Patti, A.D. Mackie, F.R. Siperstein, Monte Carlo simulation of self-assembled ordered hybrid materials, Langmuir 23 (2007) 6771-6780.

39. A. Patti, F.R. Siperstein, A.D. Mackie, Phase behavior of model surfactants in the presence of hybrid particles, J. Phys. Chem. C 111 (2007) 16035-16044.

40. A. Patti, A.D. Mackie, V. Zeleňák, F.R. Siperstein, One-pot synthesis of amino functionalized mesoporous silica materials: Using simulations to understand transitions between different structures, J. Mater. Chem. 19 (2009) 724-732.

41. A. Patti, A.D. Mackie, F.R. Siperstein, Monte Carlo simulations of self-assembling hexagonal and cage-like bifunctional periodic mesoporous materials, J. Mater. Chem. 19 (2009) 7848-7855.

42. A. Patti, Monte Carlo simulations of self-assembling star-block copolymers in dilute solutions, Colloids and Surfaces A: Physicochem. Eng. Aspects 361 (2010) 81-89.

43. F. Kleitz, J. Blanchard, B. Zibrowius, F. Schuth, P. Agren, M. Linden, Influence of cosurfactants on the properties of mesostructured materials, Langmuir 18 (2002) 49634971.

44. P.V. Dankwerts, The reaction of $\mathrm{CO}_{2}$ with ethanolamines, Chem. Eng. Sci. 34 (1979) 443446. 